
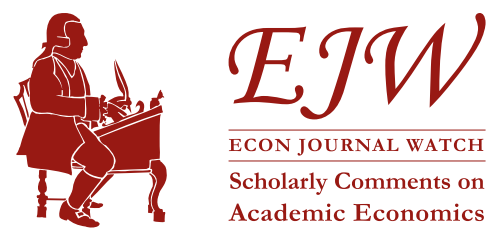

ECON JOURNAL WATCH 13(3)

September 2016: 490-502

\title{
How To Do Well While Doing Good!
}

\author{
Gordon Tullock
}

LINK TO ABSTRACT

Economic research always has the potential of contributing to public welfare since improved knowledge can have an effect on the world that is desirable and is unlikely to have an effect that is undesirable. Nevertheless, I would estimate that the average article in economic journals these days has very little prospect of contributing to the well-being of the world. Most economists know this and worry more about publication and tenure than about the contribution their research will make to public welfare. The argument of this chapter is that virtue does not have to be its own reward. The average economist can benefit his career while simultaneously making a contribution to the public welfare.

Consider, for example, the case of the dissolution of the Civil Aeronautics Board (C.A.B.). In 1937, Congress cartelized the U.S. air transport industry, establishing a government agency, the C.A.B., to supervise and control the cartel. As a result, in the United States air transportation prices were held well above their equilibrium, even though they were lower than the prices charged internationally and in Europe. ${ }^{1}$

* This essay was published in David C. Colander, ed., Neoclassical Political Economy: The Analysis of RentSeeking and DUP Activities (Cambridge, Mass.: Ballinger Publishing Company, 1984), pp. 229-240. We have made a very few minor corrections and omitted an unnecessary section header. For kind permission to reprint the essay here, Econ Journal Watch thanks Mary Lou Gunderson and the estate of Gordon Tullock.

1. The apparent reason that American airlines' prices were lower than those in Europe was not that our airlines were any less monopolistic but that they were more efficient, with the result that the optimum monopoly price for them was lower than the optimum monopoly price for such monsters of inefficiency as Air France or Japan Airlines. 
In 1984, the C.A.B. was abolished, and it is clear that economists played a major part in its destruction. A group of economists (Jim Miller is the one that I know best) devoted a great deal of time and effort to economic research in connection with the airline industry and to what we may call public relations activities in connection with it. They formed an improbable political alliance between the American Enterprise Institute and Senator Kennedy for the purpose of bringing the control device to an early grave. Further, they were able to convince some of the airlines that they would gain from the elimination of the C.A.B.

As far as I can see, when these economists began their campaign there was substantially no public interest in the matter at all; most people and politicians would have argued that the C.A.B. was necessary in order to prevent the airlines from exploiting the passengers. It is also true that most of the economists who looked at the problem had approved the regulation. It should be said that a good many of the economists that looked at it were members of that small subset of the profession who were professional public utility economists and whose own personal income depends very heavily on the continued existence of these boards for which they can give expert testimony. Miller could have joined this small group but chose the other side, and in view of his subsequent career, it is hard to argue that he was not right, both from the standpoint of the public interest and his own career.

I do not want to, indeed am not competent to, go into the detailed history of this successful campaign, but I should like to point out two important factors: The first is that the average citizen, if he or she had known the truth about the C.A.B., would always have been opposed to it. This is one of the reasons why you can argue that it was in the public interest. The second is that it was not too hard to get the actual story out. The problem was mainly that of explaining the matter to the politicians and the media. This is not necessarily easy since neither of these groups have any particular motive to think hard about the true public interest. They are both much more interested in the image of public interest currently in the minds of the citizenry. But to say that it is not easy, is not to say that it is impossible, and here we have a clear-cut case where it was accomplished. The theme of this sermon is "Go Thou and Do Likewise."

The C.A.B. is not by any means the only example. Banking regulation has to a large extent collapsed in recent years. This was to a considerable extent the result of technological developments, but the existence of a vigorous group of economic critics of the regulations was no doubt important. After all, the regulators could have just changed their regulations to take in the new technology. The fact that they did not was certainly, to some extent, the result of the work of the antiregulation economists in this area. The partial deregulation of the trucking industry is almost 
entirely the result of economic activity and, indeed, during the latter part of the Carter administration an economist was acting chairman of the ICC. ${ }^{2}$

In all of the cases originally the majority of the economic profession was on the wrong side, favoring regulation. This is one of the problems we face when we talk about economists having a good effect on policy. We must admit that in the past economists have frequently had a bad effect. Good economists have always had a good effect, however, and those who had a bad effect were bad economists. This is not just an ad hoc argument; I believe that one can look into the matter and discover that the people who favored such agencies as the ICC at the time they were set up were markedly poorer economists than the ones who objected to it.

There are other striking examples. In 1929 the United States was probably the world's highest tariff nation. It is true that during the intervening years we have developed a habit of setting up quotas and voluntary agreements, but even if you add those on, we still are a very low trade barrier nation. This change seems to be almost entirely an outcome of steady economic criticism. Certainly, it is very hard to put your finger on any other reason for the change.

Once again however, the history is not clear. The protective tariff, of course, has long been a bette noire of the economists, but a review of the advanced theoretical literature over the last years shows far more discussion of optimal tariffs than of the desirability of getting rid of tariffs. This is particularly surprising because the articles dealing with optimal tariffs rarely, if ever, point out that their optimality is a rather special one and that, in any event, it would be impossible to calculate an optimal tariff in the real world. ${ }^{3}$ Still, the majority of economic opinion was always against protective tariffs even if this point of view did not get much attention in the technical journals. In a way the success of the tariff-lowering movement depended a great deal on the fact that the secretary of state for some twelve years was a former southern congressman who had learned free trade in his youth and stuck with it. Cordell Hull, of course, has been dead for many years, but the trend that he started continued. Certainly, the general favorable economic climate for such cuts was important there.

What can we do now and, more specifically, what can readers do that is good but will also help them in their careers? My argument is that there are numerous instances that almost all economists can agree are rent-seeking and detract from general welfare. In such cases virtue need not be its own reward.

2. Unfortunately, this partial deregulation seems to have stopped. (I hope temporarily.) Once again, it is encouraging that most economists were opposed to this regulation.

3. It is not that the optimal tariff literature is wrong. It is that it can be misused and that economists are more likely to have a positive effect on public policy because rent-seeking forces will be pushing for a tariff that is far beyond any optimal tariff. 
Let me begin with an example on which almost all economists would agree. There are about 300 British Columbian egg producers, and some time ago it occurred to them that they were not as wealthy as they would like to be. They pressed the British Columbia government into setting up the British Columbia Egg Control Board, a cartel in which the government not only fixed prices but actually engaged in civil service employing operations. Specifically, the Egg Control Board purchased the eggs from the owners of egg factories and then sold them to the public.

The original arguments for this program (other than that it would make the egg producers wealthy), were that they would stabilize prices and protect the "family farm." They have stabilized prices. If you compare prices in British Columbia to those in Washington State, which has roughly the same conditions, it is clear they fluctuate more in Washington State. However, they have stabilized prices primarily by preventing the falls in price that periodically cause so much distress for producers of eggs in Washington. Whether this particular kind of stability is admired by the housewife, as opposed to the egg producer, is not pellucidly clear. As for protecting the "family farmer," I doubt that these enterprises really should be referred to as family farms, but it is true that there is some evidence that the average size is possibly slightly suboptimal in British Columbia.

In order to charge a monopoly price it is, of course, necessary to prevent entry into the business. This is done by the traditional grandfather clause, so that those who are producing eggs in British Columbia when the scheme started are the only ones who are permitted to do so. As a result, the wealth of the farmers has increased very greatly because the permits to produce eggs are now valuable. Indeed, for the average egg producer, the permit is more than half his total capitalization.

It should be pointed out, however, that in addition to the egg producers there is one other beneficiary of this scheme. The egg producers produce more eggs than can be sold in British Columbia at what the British Columbia Egg Marketing Board thinks is a stable price. The additional eggs are sold on the international market for conversion to things like dried eggs at whatever the market will bring.

How do I know all of this about the British Columbia Egg Marketing Board? The answer is simple. Two economists decided that it would be a worthwhile study and the Fraser Institute published it in the form of a small booklet. ${ }^{4}$ Borcherding and Dorosh thus acquired a reasonably good publication, probably quite easily. It is no criticism of the pamphlet to say that it involves no particular economic sophistication or advanced techniques. It may have been a little difficult, because I presume the Egg Board was not exactly enthusiastic about cooperating with them.

4. The booklet is The Egg Marketing Board, A Case Study of Monopoly and Its Social Costs, by Thomas Borcherding and Gary W. Dorosh (Vancouver: The Fraser Institute, 1981). 
Nevertheless, I would imagine that the cost/benefit analysis of this pamphlet, in terms of getting a publication and the effort put into it, was very exceptionally favorable. Further, the pamphlet itself certainly will make the survival of the Egg Board, at least, a little less certain, a result most economists believe would be beneficial.

Of course I hope that more is done here. The pamphlet was published by the Fraser Institute, which exists essentially for the purpose of doing this kind of thing and attempting to influence public policy by its research. The head of the Fraser Institute frequently appears on television. I would think that the prospects for the Egg Board are clearly worse than they were before all of this started. I hope that Borcherding and Dorosh follow up on this, not so much by further research although that of course probably can be done, as by trying to get other publications in the local media.

Here, I am going to suggest that they do something unprofessional; I believe economists should make an active effort to interest the local newspaper and other media in such issues. Stories of a small entrenched interest robbing the general public are the kind of story that does go well once you sell a reporter. Further, they are not particularly complicated.

Such activities are not the ones economists normally engage in; moreover, it will be a little difficult to interest newspaper reporters. Newspaper reporters tend simply to say what other newspaper reporters have said. ${ }^{5}$ Granted that reporters behave this way, they are nonetheless normally looking for a scandal which they can make headlines about, and there are innumerable examples. The licensing of private yacht salesmen in California is my favorite case of the public being protected against low commission rates, but I am sure most economists can think of a half dozen more. But let us defer further discussion of general publicity for now.

We can roughly divide various rent-seeking activities for which there is likely a consensus among economists that they are indeed rent-seeking into three categories: those that involve spending money in a way that in the standpoint of the average taxpayer is foolish but that benefits a particular group, those that involve fixing prices above equilibrium, and those that involve obtaining cartel profits by restricting entry into a business. ${ }^{6}$

Economists have not been very successful in their efforts to stop federal government expenditures resulting from rent-seeking. Jack Hirshleifer, for example, devoted a good deal of time and energy, together with a number of experts

5. The "deregulation" that has been so successful in recent years in the United States is an example. It has become more or less a fad with most of the correspondents for The Washington Post who were in favor of it without having any clear idea why.

6. I leave aside here those cases in which if we look only at the short run, as unfortunately the voter does, the beneficiaries outnumber the people who pay. Price controls on gas are a current example. 


\section{TULLOCK}

in the field, in attempting to prevent the Feather River Project from being built in California. It has not been completed yet, but, on the whole, their efforts cannot be said to have made a major impact. I do not know why it is harder to stop government expenditures of this sort than the other kinds of government activity, but I suspect the problem is simply that from the standpoint of the citizens of California, the project is in fact a good one. ${ }^{7}$ Their efforts were very largely concentrated in California. The cost, on the other hand, was very largely borne outside of California. There has been relatively little in the way of efforts on the part of economists to stop locally financed expenditures where I think they could have more impact. In making attacks on local expenditures, I think it is wise to keep in mind that in many cases the money actually is federal. It is not unwise of the local government to accept a gift from the national government even if the gift is not in optimal form. The conclusion that can be drawn is that rent-seeking can most often be stopped if the groups that are bearing the cost can be informed.

Turning to the other two categories, entry restriction and price control, most of these are state and local regulations, although there are, of course, federal examples. At these lower levels of government the beneficiaries and the injured groups are somewhat closer together and informing the injured group is somewhat easier. Further, an individual's activities are more likely to have effect in such a restricted area, and last but not least, most of these projects are fairly simple. Thus, it seems better to concentrate anti-rent-seeking activities in these areas.

Let us begin with the cases in which the prices are fixed by some government board, with a maximum and minimum price. This is essentially the British Columbia Egg Board, and there is a simple argument to be used against it, which is that there should be no minimum price. Consumers can hardly be protected by a minimum price. If you can get the minimum price out, the pressure group that set the thing up in the first place will probably see to it that the maximum price is eliminated.

At this point, I should perhaps mention the standard rationalization, ${ }^{8}$ that advocates of the minimum price will almost certainly use. They will allege that if the minimum price is not imposed then some company with a lot of money will cut prices, drive the competition out of business, and then exploit its monopoly. This argument is eliminated by not arguing against the maximum price, and instead leaving that to the regular political process. The lesson here is a simple one: The best economic reasoning is not always (indeed, it is generally not) the best politics. Policy economists must formulate arguments that are most liable to lead to the desired outcome, not that are most elegant.

7. Ignoring, of course, those particular farmers who will be damaged by the canal across the delta. 8. I encountered it in high school. 
Restrictions on entry are subject to a variety of forms of arguments. The formal rationalization - that is, that they make certain that the service provided is on a certain level of quality — can be countered by Milton Friedman's “certification," which is that the state or local government could provide certificates of competence to anyone who passed their regulations, but not prohibit people who do not have such certificates from practicing provided that there was no fraud. In other words, the person without a certificate would not tell people who solicited his services that he had one. This procedure would probably eliminate most of the monopoly gains and convert the present arrangements into something that might even be socially desirable.

The usual argument against this, of course, is that people are not bright enough even to look at the certificate. (Why people who argue this way think that people are bright enough to vote, I don't know, but they do.) To counter this argument one can move to a second line of defense, by pointing out that these regulations are not and, in fact, make very little effort to pretend to be, efforts to raise the quality of services.

Uniformly, when such restrictions are put on, everyone now in the trade is grandfathered in. Indeed, that is the reason they are put on-the current people in the trade want to have their lifetime income raised by reducing competition. Clearly, if everybody now in the trade is competent without investigation of any sort, it is unlikely that an investigation is of any use. Thus, all new proposals of this sort can be opposed quite readily.

If we turn to the older ones, there may well be an examination, usually an irrelevant examination, but the examination is given only to new entrants. The appropriate argument here is simply that it is possible for a person practicing, whether as a doctor or as a plumber, to fail to keep up with new developments, forget old developments, or, for that matter, become a dipsomaniac. It would be desirable, therefore, that everyone in the trade not only be examined when he enters but be reexamined from time to time. It is hard to think of any argument against this, but it clearly would eliminate the political pressure for the restriction if the restriction had to take the form of continuing examinations.

Finally, there is a constitutional argument. The Supreme Court has held that requiring a waiting period for a new entrant into a state before he can go on relief violates his constitutional rights to travel freely. Prohibiting him from practicing his trade as a carpenter would also do so. Of course, if the restriction were literally evenhanded - that is, if the New York restriction on carpentry is the same for New Yorkers as for Californians who want to migrate to New York, then this constitutional argument would not exist. Such a restriction, however, would imply that if all people who are practicing carpentry in New York at the time the law was passed are admitted without examination, people who are practicing carpentry in other 


\section{TULLOCK}

states at that time should also be admitted without examination. If we could get the Supreme Court to hold that this is what the Constitution said, we could feel confident that there would be absolutely no political effort to establish new restrictions on entry in the states and local governments throughout the United States.

If an examination for carpenters has been in existence for a long time so that there are not very many carpenters from other states who were carpenters at the time that the original carpenters were grandfathered in, there is a somewhat more difficult constitutional problem. Here, however, an argument would be needed that the examination is not really intended to certify people's ability as carpenters but to prevent migration from other states. It seems to me that the simple fact that the examination is not given regularly to people who are already practicing in order to make certain that they are retaining their skills, and not becoming dipsomaniacs, would be adequate here. Such constitutional arguments may or may not be successful in the courts. I recommend its use in economic arguments, even though it is not strictly relevant, simply because I think it will have a persuasive effect on the average voter.

In making any anti-rent-seeking argument, one should always point out that the data are inadequate (one can also imply in a tactful manner, that the reason that the data are inadequate is that the guilty are concealing or keeping secret evidence of their guilt). More data are always needed and generally the pressure group is to some extent unwilling to provide data because it fears strengthening your argument. Mainly, however, this argument places you in a very good position for rebuttal. Almost certainly, the pressure group representatives will argue that you are simply ignorant in their field. A response in which you say that your ignorance is partly because they are keeping secrets and ask them to provide further information generally would be helpful. In the unlikely event that they do provide additional information, of course, you have opportunity for further and better research.

A second argument that inevitably can be made is that the pressure group has something material to gain from its activities. Although we, as economists, do not regard this as in any way discreditable, the average person does. In fact, the pressure group will normally be arguing that its existence benefits people it in fact injures, but they will normally not deny that its own members are gaining, too. You will thus merely be giving strong emphasis to something the pressure group tends to pass over lightly.

If individual economists would select some blatantly undesirable activity, preferably of a state or local government, and become a modest expert on it, it is my contention that the economy would improve. Doing so does not involve a major investment. In general, these programs are not complicated, but nevertheless becoming an expert will involve some work. After becoming an expert, the economist should attempt to get media publicity for the position with the result first, 
of certainly attracting the attention of the pressure group, which may or may not be useful, and, second, if the economist pushes hard enough and is persistent, he probably will have at least some effect on the activity of the pressure group.

Here, I should emphasize that though I am suggesting this as an individual effort, there is no reason why small collectives of economists should not be involved, and there is certainly no reason why you should not seek out the support of other groups. The League of Women Voters, for example, tends to go about looking for good causes and you may be able to improve their taste. There are also various business groups, Rotary Clubs, and so on that are always on the lookout for a lecturer and that would give you an opportunity to provide some influence.

Persistence will, however, be necessary. The pressure group will continue and a mere couple of months' noise about it is helpful but unlikely to accomplish a great deal. Persistence is not difficult, however. Once you have passed the threshold of knowing enough about the organization so that you can regard yourself as a modest expert, it is very easy to keep up with further developments and incorporate additional data into your analyses. Further, your contacts with the media are apt to be self-reinforcing. After you have convinced people that you know a great deal about, let us say, controls on egg production, you are likely to find television program directors asking you questions about all economic matters. You should answer them, of course, to the best of your ability, and this will not only, we hope, contribute to the economic information of the public but also give media representatives an idea of your expertise so that when you bring up the subject of eggs or whatever it is, they are likely to pay attention.

Most economists only occasionally give lectures to something like the Rotary Club. I am suggesting that this aspect of professional life be sharply increased. Furthermore, I am suggesting that you become an expert on some rather obscure topic instead of giving your lecture to the Rotary Club on what is right or what is wrong with Reaganomics. This is indeed a change from the normal academic life but not a gigantic one. I am not suggesting that you devote immense amounts of time to these joint projects, merely that you do indeed devote some time to them. In a way it may be a pleasant change from the more profound and difficult work that I am sure mainly occupies your time.

So far I have been telling you how you can do good and have not explained why I think you can also do well. The first thing to be said is that of course the kind of research I am proposing does have some potential for publication in the regular economic literature. The Journal of Law and Economics, The Journal of Political Economy, Public Policy, and others all are interested in such articles. I would also suggest that the political science journals would be interested, although it would be necessary to make a few changes in your approach if you submitted articles to them. 
But while all of these people would be interested and, I think, the prospects for publication are quite good, it has to be said that if a great many economists begin working in this area it would rapidly exhaust the desire for such articles in these journals. After awhile, only the very best of such articles could be published there. Further, in this case "best" would not refer entirely to the quality of the work but also to the importance of the subject matter. A new twist in cartel economics would, for example, probably be publishable when hundreds of studies of specific cartels would not.

So far, of course, the tolerance of these journals for this kind of article has by no means been exhausted and those of you who get in first could no doubt take advantage of that tolerance. Once we turn from this kind of journal publication, however, there are a number of other places with gradually decreasing prestige where you can get published. There is now a chain of economic institutes who are in general interested in studies of this kind of cartel. ${ }^{9}$ The Borcherding and Dorosh pamphlet is a good example. Clearly this is a perfectly suitable publication to put on your vitae even if it does not carry quite so much weight as publication in The Journal of Political Economy. I, as a matter of fact, have three such things on my own vitae. Indeed, I would imagine that in cost/benefit terms these things are considerably more highly paying than JPE articles because although the payoff is not as high, the cost of producing them is also low.

Below that level there is the possibility of fairly widespread publication in such things as articles in local newspapers, letters to the editor, and so on. These are not great publications and you might want to indicate on your bibliography that you think they are not. For example, you could have a separate section for newspaper articles and letters to the editor. You might even mention your appearances on TV in this separate section.

With respect to these less important articles, speeches, and the like, the payoff in academic life is, of course, quite low per unit. Most universities, however, regard activity in the public arena as meritorious and pay it off in higher wages. It also carries with it the advertising value that an article in The Journal of Political Economy carries, although, once again, at a lower level.

But although these are less important publications, their cost is also quite low. Once you have become an expert in this area you could grind them out practically at will, producing a letter to the editor, for example, in a half hour. Thus, once again, the cost-benefit analysis from a pure career standpoint seems to be positive.

But this may immediately raise a question in your mind. How do I know that better information is likely to cause the end of these special-interest arrangements? After all, they have been in existence a long time and most economists know about

9. The bulk of them owe their origin to the energies of Antony Fisher. 
them in general even if the public does not. They do not seem to be very secretive. I believe that they depend on either ignorance or misinformation on the part of the public. My reasons for believing so are two: First, if you discuss any of them with average voters it will turn out that they have never heard of them, or if they have heard of them, they are badly misinformed about them. In the case of the British Columbia Egg Board, the average voter probably does not know that there is such an organization. The voter who does probably has bought the argument that the organization stabilizes prices and protects the family farm.

But in addition to this informal public opinion poll, there is another and, in my opinion, more important reason. If we think of the British Columbia Egg Board, any economist could quickly arrange a set of taxes on eggs together with direct subsidies to the people who were in the business of producing eggs ${ }^{10}$ that would make both the customers and the producers of the eggs better off. We do not see this direct subsidy being used. Why do pressure groups not simply aim at a low tax on the entire population that is used to pay a direct sum of money to them rather than these clearly non-Pareto-optimal arrangements that we in fact observe? I think the only available explanation for this is that they know that a certain amount of confusion and misdirection is necessary. A direct cash transfer, a tax of $\$ 10$ per family in British Columbia for the purpose of paying a pension to the 300 people who happen to own egg factories at the time the program was put into effect, would never go through because it is too blatant and obvious. It is necessary that these things be covered by some kind of deception. Granted that I am right about this — that these programs require that the people be misinformed-informing them is likely to terminate the program. No politician is going to tax all of his constituents a small sum of money in order to give a large sum of money to a small group no matter how well organized that small group is if everyone knows that is what he is doing. Economists can see to it that they do know.

Note here, also, that the nature of the mass media is on your side. The mass media all aim at large audiences. The small pressure group does not have much chance of getting the attention of the mass media except, possibly, unfavorable attention. The small pressure group very likely has its own journal, which it uses for internal communication, but the owner of a TV station or a newspaper will tend to come down for his customers en masse, not a tiny minority of his customers. Thus, not only is secrecy and deception necessary here but the nature of the mass media means that unmasking of these villains is likely to be popular with those who want to make money in the media business.

I am sure all of this sounds rather wild to most of you. I gave an earlier version of this paper at my own university and a young ABD, who had been listen-

10. Some of these might, of course, decide to stop producing eggs and move to Hawaii on the subsidy. 
ing and apparently could not believe his ears came up afterward and asked me whether it was really true that I was suggesting that he not only study up on some local government-managed cartel but seek publication in places other than the JPE. I assured him that was my objective. He went away looking astounded, not, I think, at the brilliance of my ideas, but at the eccentricity.

This particular young man will, I think, have great difficulty getting any publications ever in the JPE. Competition is stiff (even to this day I have about half of my submissions turned down ${ }^{11}$ ), and most economists will never get a single article published in a leading journal. Still, I assume all of you are members of that small minority who do occasionally break into print in such places as JPE, the AER, and the QJE.

Turning to the problem of the man who does have great difficulty getting anything published, something on his vita is better than nothing, and the proposal that I am making is a way in which he can pretty much guarantee he will have at least something on his vita. For the more productive economist, who does currently produce articles for the leading journals, it is still helpful to add additional items even if these additional items are not of Nobel Prize quality. Once again, the cost of producing these things is comparatively low, so you make a good deal per unit of effort.

Even if there were no beneficial impact on your career, nevertheless, I would urge it on you. All of us are, to some minor extent, charitable and this is a particularly convenient way for economists to work out their charitable feelings. Getting rid of the British Columbia Egg Board might not impress you as a major accomplishment, but individuals can expect to have only small impacts on the massive structure that we call modern society. It is likely that you will do more good for the world by concentrating on abolishing some such organization in your locality than the average person does-indeed, very much more. It is an unusual form of charity, but a form in which the payoff would be high. But although such work falls squarely in the path of virtue, it also has positive payoffs. You can, to repeat my title, do well while you are doing good.

\section{References}

Borcherding, Thomas, and Gary W. Dorosh. 1981. The Egg Marketing Board: A Case Study of Monopoly and Its Social Costs. Vancouver: Fraser Institute. Link

11. I have a large collection of unpublished articles. 


\section{About the Author}

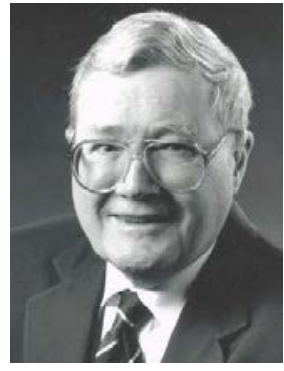

Gordon Tullock (1922-2014) was Professor Emeritus of Law at George Mason University. Tullock was born and raised in Rockford, Illinois, and earned his J.D. from the University of Chicago. A prolific political economist, Tullock authored several books, among them The Calculus of Consent (with James M. Buchanan), The Politics of Bureaucracy, The Organization of Inquiry, and The Economics of Non-Human Societies; a ten-volume collection of his Selected Works was published by Liberty Fund in 2004-2006. Tullock's many notable activities included his founding and longtime editorship of the journal Public Choice. As of September 2016, his Google Scholar page (link) showed over 39,000 citations.

Go to archive of Watchpad section Go to September 2016 issue

Discuss this article at Journaltalk:

http://journaltalk.net/articles/5931 